\title{
Peptides on a rescue mission against the hazardous cidal chemicals used in Eastern Indian Agriculture: An in-silico approach based on field survey in 2020
}

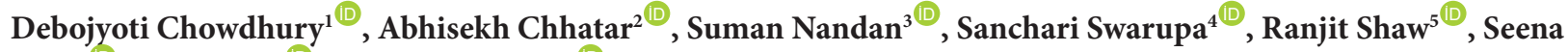 \\ Basu $^{6 \mathbb{D}}$, Nitin Atre ${ }^{7 \mathbb{D}}$, Dinesh Khedkar ${ }^{{ }^{*} \mathbb{D}}$ \\ ${ }^{1}$ Department of Biochemistry and Biophysics, University of Kalyani, Kalyani, Nadia, West Bengal, 741235, India \\ ${ }^{2}$ Department of Life Science, National Institute of Technology, Rourkela, Odisha, 769008, India \\ ${ }^{3}$ Department of Mathematics, University Institute of Technology, University of Burdwan (UIT), Bardhaman, West Bengal, 713104, \\ India \\ ${ }^{4}$ Department of Chemistry, Division of Biochemistry, Savitribai Phule pune University, Pune, Maharashtra, 411007, India \\ ${ }^{5}$ Department of Zoology, Banaras Hindu University, Varanasi, Uttar Pradesh, 221005, India \\ ${ }^{6}$ Department of Microbiology, Vijaygarh Jyotish Ray College, University of, Calcutta, West Bengal, 700032, India \\ 'Bioinformatics and Data Management, ICMR - National Institute of Virology, Pune, Maharashtra, 411021, India \\ ${ }^{8}$ Department of Botany, Shri Shivaji Science College, Amravati, Sant Gadgebaba Amravati University, Amravati, Maharashtra, 444603, \\ India
}

\begin{abstract}
Background: The use of poisonous agrochemicals is both necessary and menacing for a farmer. The long-term hazards of chemicals can even be life-threatening to many people. Recently, the adverse effects of such chemicals on the environment and human health received serious attention throughout the world. In an Indian context, the usage of the chemical sprays has costed many lives and influenced vital organs to the greatest extent. This serious situation advocates the search for ways to prevent the inhalation and absorption of these chemicals into the body. The present study was conducted to evaluate different types of chemical sprays, their impact, and explore remedial ways to neutralize their toxic effects.

Methods: Alpha-cypermethrin, phorate, fenobucarb, buprofezin, and mancozeb were selected for binding based on the feedback of severity in actions reported by the respondents and statistical analysis of different physical and chemical parameters. Chemical similarity analysis of the 39 cidal chemicals was performed to predict the binding similarity with respect to the above-mentioned 5 seed molecules. These five chemicals were docked with three different proteins 121p GTPase HRas, Torpedo acetylcholinesterase, and trypanosoma phosphoglycerate kinase, selected based on the common target prediction.

Results: Common target prediction revealed that these chemicals have an affinity to bind these proteins with a higher binding interaction towards the aromatic amino acid residues and those capable of $\mathrm{H}$-bonding, escorted by a predilection towards acetylcholinesterase.

Conclusion: The in-silico findings are the basis to propose that acetylcholinesterase can be considered as a potential binding agent to trap fatal agrochemicals.

Keywords: Agrochemicals, Molecular docking analysis, Cypermethrin, Buprofezin, Fenobucarb, Acetylcholinesterase

Citation: Chowdhury D, Chhatar A, Nandan S, Swarupa S, Shaw R, Basu S, et al. Peptides on a rescue mission against the hazardous cidal chemicals used in Eastern Indian Agriculture: An in-silico approach based on field survey in 2020. Environmental Health Engineering and Management Journal 2021; 8(2): 107-122. doi: 10.34172/EHEM.2021.14.
\end{abstract}

\section{Article History:}

Received: 8 December 2020 Accepted: 9 February 2021 ePublished: 13 May 2021

\section{Introduction}

Agriculture is the foundation stone of the Indian economy. It accounts for $13.9 \%$ of the gross domestic product (GDP) and almost $54.6 \%$ of the population is employed in the croplands (1). Various chemical sprays are used to protect crop plants from attacks of pests such as insects, rodents, nematodes, fungi, and weeds. The rise in population has led to an increased food demand, which has enhanced dependence on the cidal sprays (2). Although these chemicals have a significant role in improving the crop 
yield by controlling vector-borne diseases, their consistent long-term use results in inconsequential health effects, surpassing their beneficial effects $(3,4)$. According to the World health Organization (WHO) report, about 3 million people in the world die due to pesticide poisoning every year. Amongst these 3 million, 2.2 million belong to the developing nations (5). Due to direct exposures, farmers become the principal victims of pesticide-imposed health risks.

According to the WHO recommended classification of pesticides by hazard and guidelines to classification in 2019 (6), pesticides are categorized as class I-a (extremely hazardous), I-b (highly hazardous), II (moderately hazardous), III (slightly hazardous), and U (unlikely to present acute hazardous). The pesticides predominantly used in Eastern India cover all these categories with a biasedness towards the class I and II categories. These toxic chemicals sometimes escape from the body's mechanism of toxin excretion, thereby are being absorbed in the circulatory system (7) and thus, lead to a wide range of human health hazards such as headache, nausea, vomiting, reproductive harm, endocrine disruption, nervous system disorders, and even cancer (8). Exposure to pesticides can occur via various exposures including oral, inhalation, dermal, and ocular (9). The pesticides with similar chemical structures or modes of toxic action undergo chemical ligand interaction with similar biomolecules of biochemical pathways. Based on their chemical composition, synthetic pesticides can be classified as organochlorines (DDT, BHC), organophosphates (dichlorvos), carbamates (carbaryl, fenobucarb), and pyrethroids (alpha-cypermethrin, lambda-cyhalothrin, permethrin). Organophosphates and organochlorines are potential acetylcholinesterase inhibitors, which cause a permanent overlay of acetylcholine across neural synapse leading to nerve impulse failure (10). Similarly, carbamates can bring about neurotoxicity in the affected subjects (11). Organochlorine insecticides also show evidence of producing adverse effects in different organs (12) by binding to thyroid hormone receptors (13).

Along with interaction with protein ligands, agrochemicals have also shown changes in the expression of mRNAs. For example, prevalent pesticides like monocrotophos and endosulfan decrease the expression of AAK-2 mRNA and A1CF mRNA, respectively (13). Apart from these mRNAs, non-coding RNAs like the miRNAs are also involved in cytotoxicity caused by the pesticides (14). The toxic effect of these cidal chemicals may be dependent on their three-dimensional (3D) structures. For example, chiral pesticides and insecticides can impose enantioselective toxicity on humans and other mammals (15).

The cidal chemicals like pesticides entering the body through the mouth (ingestion) or inhalation have been reported to cause serious illness, severe injury, damage to the nose, throat, lung tissues, or sometimes even death
(16). Since chemicals are dispersed mainly by hydraulic sprayers, the most significant potential for poisoning via respiratory exposure has occurred due to vapors and extremely fine particles of spray solution. It has been found out that the chemical poisoning via inhalation route has more deleterious effects than the dermal route since the lung is the primary target of these toxicants (17).

The paucity of information and research regarding the chemical use pattern, updated knowledge on hazards created by these chemicals, is creating challenges in combating this scary situation. There are studies designed to eliminate pesticides from the environment (18) but not much efforts have been made to stop them before entering the human body through direct exposure, specially those which are affordable to farmers. The present study was designed to evaluate the current chemical usage pattern in Eastern India and find a way for preventing the perilous effect of the cidal chemicals used on croplands by farmers using the knowledge obtained from the evaluation. Here, in-silico binding studies of some pesticides with a few proteins pave the path towards finding a potential binding agent that can trap the cidal chemicals. The present research suggests a trapping agent against the cidal chemicals that is biodegradable with the potential of being reusable and advantageous over the currently used ones. This paper also acts as a reminder of the threats that these chemicals impose on the human life.

\section{Materials and Methods}

The present study was conducted to understand the prevalence of cidal usage and its effect on farmers across the eastern region of India. The most frequently used chemicals with potential hazards were shortlisted from the responses of the users. These chemicals were analyzed for physical and other properties. The selected chemicals were docked for a suitable protein to explore an opportunity to report the best candidate to trap hazardous chemicals before entering the human body.

\section{Baseline survey}

This baseline study was conducted in two major states of Eastern India, namely West Bengal and Odisha. The present study was focused over some districts of these two states, including Hooghly, Nadia, Birbhum, Purba Barddhaman, Paschim Barddhaman, South 24 Paragana, North 24 Paragana, Purulia, Bankura, East and West Medinipur from West Bengal and Bargarh, Sundargarh, Sambalpur from Odisha (Figure 1). From the abovementioned 14 districts of Eastern India, 600 respondents were interviewed for the survey. They were from various agriculture fields encompassing farmers, sellers of cidal chemicals, agriculture officers, agriculture business persons, and daily wage laborers. A questionnaire was prepared, which comprised of demographic information such as age, sex, types of chemical sprays used in fields, types of crops grown and menace by pests, farm size 


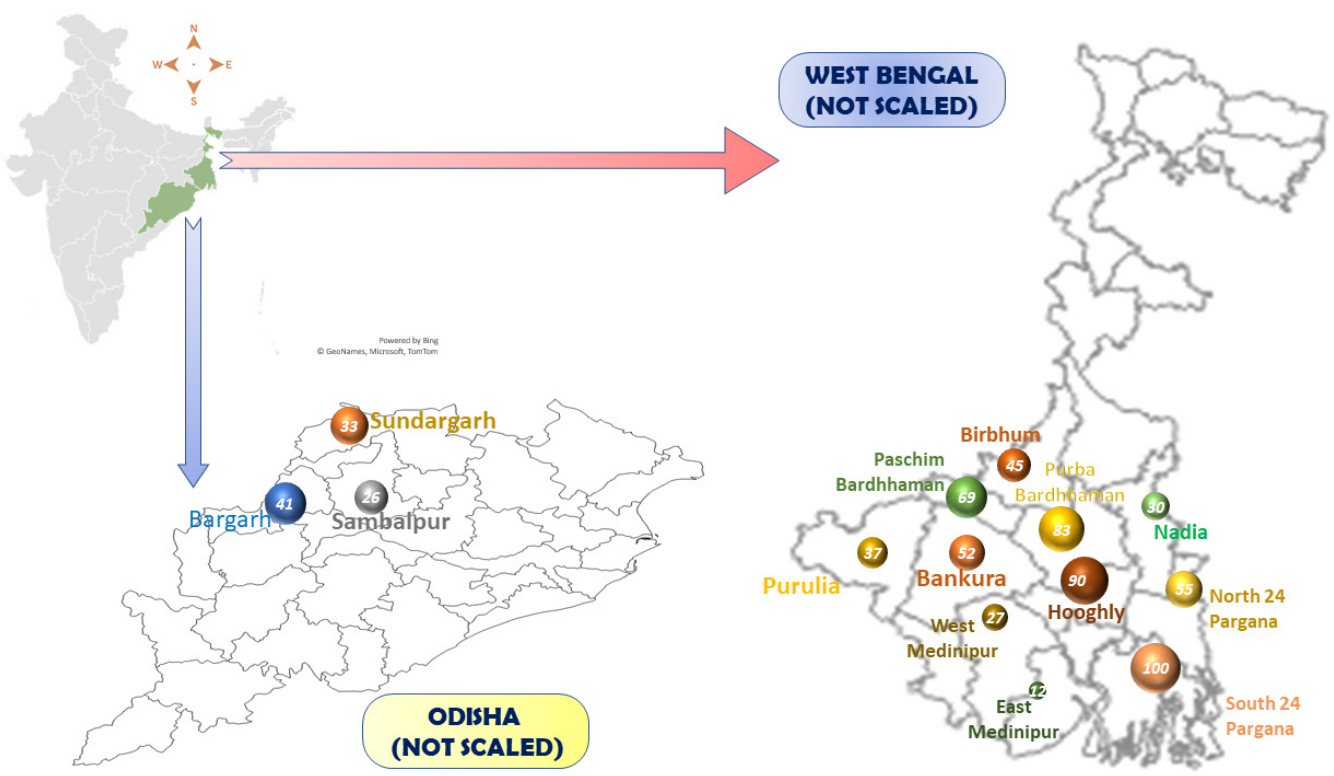

Figure 1. Number of respondents taken part in the survey along with the districts of West Bengal and Odisha, the two states of Eastern India where the survey was conducted. The number of subjects from each district is presented in number inside the spheres with different colours for different districts.

(hectares) category of sample households, symptoms experienced, if any, after the use of agrochemicals, knowledge of the toxicity of agrochemicals, and preventive measures used while spraying chemicals.

\section{Analysis of cidal chemicals}

From the baseline survey, the agrochemicals reported were studied using the PubChem database (19). The physical and chemical properties, toxicity, bio-activity like mutagenic, tumorigenic, irritant properties, and reproductive effectiveness of the selected chemicals were checked using DataWarrior.

\section{Tools used in computational approach}

For the statistical analysis, Wessa online statistics tool was used in the present study. Chemical similarity analysis was done using ChemMine $\mathrm{R}$ and DataWarrior. Swiss TargetPrediction tool was used to identify the common protein targets for the selected chemicals. The docking studies were done using mcule Web tool. The docking interactions were further studied using Discovery Studio client 2020. The methods are further elucidated below.

\section{Selection of chemicals for binding:}

To conduct the docking studies, five most frequently used chemicals, as reported by the respondents in the present study, were selected. A correlation between all the agrochemicals and their physical characteristics was established by statistical treatment taking melting point and oral LD50 value as parameters. A statistical distribution curve of the melting points of the chemicals, generated by an online platform (Wessa Free Statistics tool) (20), was used to distribute all the agrochemicals into four quartiles, and five were selected from significant quartiles. The percentage distribution chart classifies agrochemicals into insecticides, herbicides, fungicides, and a univariate data plot.

\section{Chemical similarity analysis}

Chemical similarities amongst the 39 chemicals tracked from the survey were established concerning five seed molecules (alpha-cypermethrin, buprofezin, phorate, mancozeb, fenobucarb) using Jaccard's Index (Tanimoto Coefficient and Dice's Coefficient) (21). The chemical similarity analysis was performed using ChemmineR (21) and DataWarrior tool (22). The DataWarrior FragFp analysis was performed to generate a similarity score where the least similarity range was set to $80 \%$.

\section{Selection of target proteins}

Protein targets were predicted with the help of the Swiss TargetPrediction Web tool. The SMILES notations for the selected compounds from PubChem were used to predict target proteins using Swiss TargetPrediction Web tool (23). The targets with the best probability values were selected, and the PDB IDs with the lowest resolution were selected for docking studies. The sequence identity and similarity analysis of the proteins were done using SmithWatermen sequence alignment (24) in the RCSB-PDB protein comparison tool.

\section{Docking of the selected chemicals with proteins}

The dockings were done using mcule 1-click Docking Web tool, which runs on AutoDock Vina Docking algorithm. The best docking poses were downloaded and visualized in the Discovery Studio 2020 client (DS). The 
receptor-ligand interactions of the agrochemicals with the key amino acid residues on the target proteins were recorded with a special focus on non-covalent attractive interactions.

\section{Results}

The in-depth survey in the study area revealed lifethreatening evidences due to the naive usage of agrochemicals. All the chemicals prevalently practiced are adjudged toxic for human health by NCBI. Three different proteins including Torpedo acetylcholinesterase, trypanosome phosphoglycerate kinase, and 121p GTPase HRas, were carefully analyzed and are known as the potent protein molecules responsible for fastening the molecule through docking studies. These results are certainly promising remedy for blocking toxic agrochemicals before their entry into human systems.

\section{Survey report analysis}

In general, most of the respondents were male directly related to agriculture as the percentage of female respondents was merely about $4 \%$. The respondents' agewise distribution revealed that $23 \%$ were less than 30 years, $46 \%$ were between 30 and 40 years of age, $20 \%$ were between 41 and 50 years, $6 \%$ were under the age group of 51-60 years, and $5 \%$ were more than 60 years. $31 \%$ of them were uneducated, $35 \%$ had primary school degree, $32 \%$ had secondary school degree, and $2 \%$ have college degree. It was reported that $65 \%$ of the respondents were unaware of the hazardous effects of the pesticides, $14 \%$ were aware, and $21 \%$ were not interested. In addition, $52 \%$ were unable to read instructions on the container, $19 \%$ were able to read instructions, and $29 \%$ were ignorant. The most common symptoms experienced by $85 \%$ of the respondents were nausea, headache, tiredness, giddiness, skin, eye irritation, vomiting, and sweating. $60 \%$ experienced cough, fever, salivation, runny nose, wheezing, $28 \%$ experienced hypotension, hypertension, severe blisters, toenail damage, muscle cramp, and $17 \%$ experienced severe symptoms of seizures, anorexia, convulsions, involuntary urination and defecation. In addition to these low and moderate toxicity symptoms, many farmers were found to be suffering from serious illness like cancer, cardiovascular diseases, respiratory diseases, and renal disorders. The fact that farmers were oblivious of the toxic nature of the compounds was quite evident as only $1 \%$ used complete partial protective equipment while $70 \%$ of the respondent used towels or cloths to cover their nose and mouth, 20\% partially covered themselves using gloves or headgear, and $2 \%$ of the subjects also mentioned washing of hands and taking a bath after spraying chemicals as protective measures. Certain unethical practices of mixing pesticides with kerosene and other pesticides, re-entering into the field sprayed with pesticides, were reported. Less knowledge about the amount of concentration of cidal spray to be used and crop specificity was reported. People prefer getting checked by doctors if severe health issues occur. Some suppressed their physical discomfort using home remedies such as tamarind water, saltwater, etc. The study also revealed that the farmers stored pesticides in places such as storeroom (32.4\%), kitchen (8.2\%), and bathrooms (14.8\%) where they become easily accessible to family members, including children.

\section{Comparison of the pesticides by responses, oral toxicity, and melting point}

Interview with 600 volunteers (farmers, agricultural officers, and others related to agriculture) showed that 39 different chemicals are extensively used as pesticides, insecticides, fungicides or herbicides (Table 1) in Eastern India. $60 \%$ of these chemicals are insecticides, whereas $20 \%$ are herbicides, and the other $20 \%$ are fungicides (Figure 2a). The five chemicals used by most of the farmers are alpha-cypermethrin (18.66\%) followed by mancozeb (16.16\%), fenobucarb (16\%), buprofezin (16\%), and phorate (15.5\%). The pesticide use pattern among the farmers is graphically represented in Figure 2e. Alpha cypermethrin, fenobucarb, phorate, and buprofezin are insecticides, whereas mancozeb is used as a fungicide.

According to their oral LD50 values (Table 1), these chemicals can be categorized into four different classes according to the WHO guidelines, including Class I-a (LD50 $\leq 5 \mathrm{mg} / \mathrm{kg}$; extremely hazardous), Class I-b (LD50: 5-50 mg/kg; highly hazardous), Class II (LD50: 50-2000 $\mathrm{mg} / \mathrm{kg}$; moderately hazardous), and Class III (LD50 $\geq$ $2000 \mathrm{mg} / \mathrm{kg}$; slightly hazardous). Out of the 39 chemicals surveyed in this study, 11 belong to Class III, 23 to Class II, 3 to Class I-b, and the rest 2 belong to Class I-a (Figure $2 \mathrm{~d})$. Among the 5 chemicals that are most commonly used in Eastern India, phorate belongs to Class I-a, alphacypermethrin and fenobucarb belong to Class II whereas, mancozeb and buprofezin belong to Class III.

The statistical treatment was employed using the melting points of the chemicals (Table 1, Figure $2 \mathrm{~b}$ and 2c) for selecting the best five chemicals for docking. The range of melting points is -15 to $420^{\circ} \mathrm{C}$. The average melting point is $144.7^{\circ} \mathrm{C}$. The results showed that $25 \%$ of the chemicals come under the melting point $\leq 76^{\circ} \mathrm{C}$ category, $50 \%$ of all the chemicals have a melting point $\leq$ $141^{\circ} \mathrm{C}$, and $75 \%$ have a melting point up to $207.8^{\circ} \mathrm{C}$. Two insecticides from the first quartile, one fungicide and one herbicide from the second quartile not in the first quartile, and one fungicide from the third quartile were selected for docking studies. Therefore, these five chemicals had different melting points. The study clarified that the most effective chemicals are in the second quartile, and also, the most frequently used pesticides belong to this region. From the statistical distribution (fitted normal density), the most hazardous chemical should be in the range of the third quartile. The sample size was 39 and the sample variance was 99.71128 and there is no reason to reject the null hypothesis $\mathrm{H}_{0}$ 142.5), where type I error is taken as 
Table 1. List of chemicals extensively used in Eastern India with their type, oral and dermal LD $_{50}$ values, melting point, and corresponding number of respondents

\begin{tabular}{|c|c|c|c|c|c|}
\hline Chemical & Agrochemical information & Oral LD50 (mg/kg) & Dermal LD50 (mg/kg) & Melting Point $\left({ }^{\circ} \mathrm{C}\right)$ & No. of respondents \\
\hline Profenofos & Insecticide & 358 & 277 & - & 23 \\
\hline Pymetrozine & Insecticide & 5000 & 2000 & 217 & 40 \\
\hline Buprofezin & Insecticide & 5000 & 2000 & 105 & 96 \\
\hline Diflubenzuron & Insecticide & 4640 & 10000 & 239 & 27 \\
\hline Butachlor & Herbicides & 5010 & 13000 & -2.8 & 52 \\
\hline Cyhalofop-butyl & Herbicides & 2000 & 35000 & $>270$ & 37 \\
\hline Emamectin benzoate & Insecticide & 2950 & 2000 & $141-146$ & 22 \\
\hline Deltamethrin & Insecticide & 129 & 2000 & 1000 & 61 \\
\hline Carbofuran & $\begin{array}{l}\text { Insecticide, nematicide, } \\
\text { acaricide }\end{array}$ & 14 & 25 & 151 & 27 \\
\hline Atrazine & Herbicides & 1780 & & $173-175$ & 41 \\
\hline Carbendazim & Fungicides & 1720 & 2000 & $302-307$ & 42 \\
\hline DDT & Insecticide & 113 & 2510 & 108.5 & 33 \\
\hline Endosulfan & Insecticide & 160 & 359 & 210 & 28 \\
\hline Endrin $20 \mathrm{E}$ & Insecticide & 3 & 18 & & 19 \\
\hline Monocrotophos & Insecticide & 135 & 1028 & 55 & 26 \\
\hline Difenoconazole & Fungicide & 1453 & 2010 & 76.0 & 27 \\
\hline Hexaconazole & Fungicide & 612 & 2189 & 111.0 & 15 \\
\hline Glyphosate & Herbicide & 5000 & 5000 & 189.5 & 41 \\
\hline Malathion & Insecticides & 2800 & 4100 & 2.8 & 45 \\
\hline Chlorantraniliprole & Insecticide & 5000 & & $208-210$ & 22 \\
\hline Propiconazole & Fungicide & 1517 & 4000 & & 24 \\
\hline Chlorothalonil & Fungicide & 10000 & & 250.0 & 38 \\
\hline Mancozeb & Fungicide & 11200 & 15000 & 172 & 97 \\
\hline Alpha cypermethrin & Insecticides & 250 & 2000 & $78-81$ & 112 \\
\hline Phorate & Insecticides & 4 & 6 & $<-15$ & 93 \\
\hline Zinc phosphide & rodenticide & 45.7 & 70 & 420 & 61 \\
\hline Parathion methyl & insecticide & 25 & 25 & 35.8 & 56 \\
\hline Paraquat & Herbicide & 150 & & $>400$ & 54 \\
\hline Coumaphos & insecticide & 140 & 860 & 91 & 29 \\
\hline Lambda cyhalothrin & insecticide & 79 & 632 & 49.2 & 42 \\
\hline Sulphur & Fungicide & 2000 & 2000 & 120 & 34 \\
\hline Bifenthrin & Insecticide, Acaricide & 375 & 2000 & 69 & 37 \\
\hline Ammonium salt of glyphosate & Herbicide & 750 & 2000 & - & 14 \\
\hline Imidacloprid & Insecticide & 450 & 5000 & 144.0 & 55 \\
\hline Acetamiprid & Insecticide & 866 & 2000 & & 51 \\
\hline Metasulfuron methyl & Herbicide & 2000 & 4592 & 162.0 & 30 \\
\hline Chlorimuron ethyl & Herbicide & 4000 & 2000 & 181.0 & 32 \\
\hline Fenobucarb & Insecticide & 140 & 420 & 31.5 & 96 \\
\hline Thiram & fungicide & 1000 & 5000 & 155.6 & 41 \\
\hline
\end{tabular}

0.05 and the obtained P-value is 0.07918 .

\section{Chemical similarity analysis}

The chemical similarity analysis using the five chemicals, namely alpha-cypermethrin, buprofezin, fenobucarb, phorate, and mancozeb (Figure 3) as seed molecules revealed that all the other pesticides except paraquat, chlorothalonil, and DDT show good structural similarity. Alpha-cypermethrin and buprofezin are closely related to the maximum number of molecules. Data analysis also showed that aromatic rings and similar types of electronegative atoms in most compounds account for the 


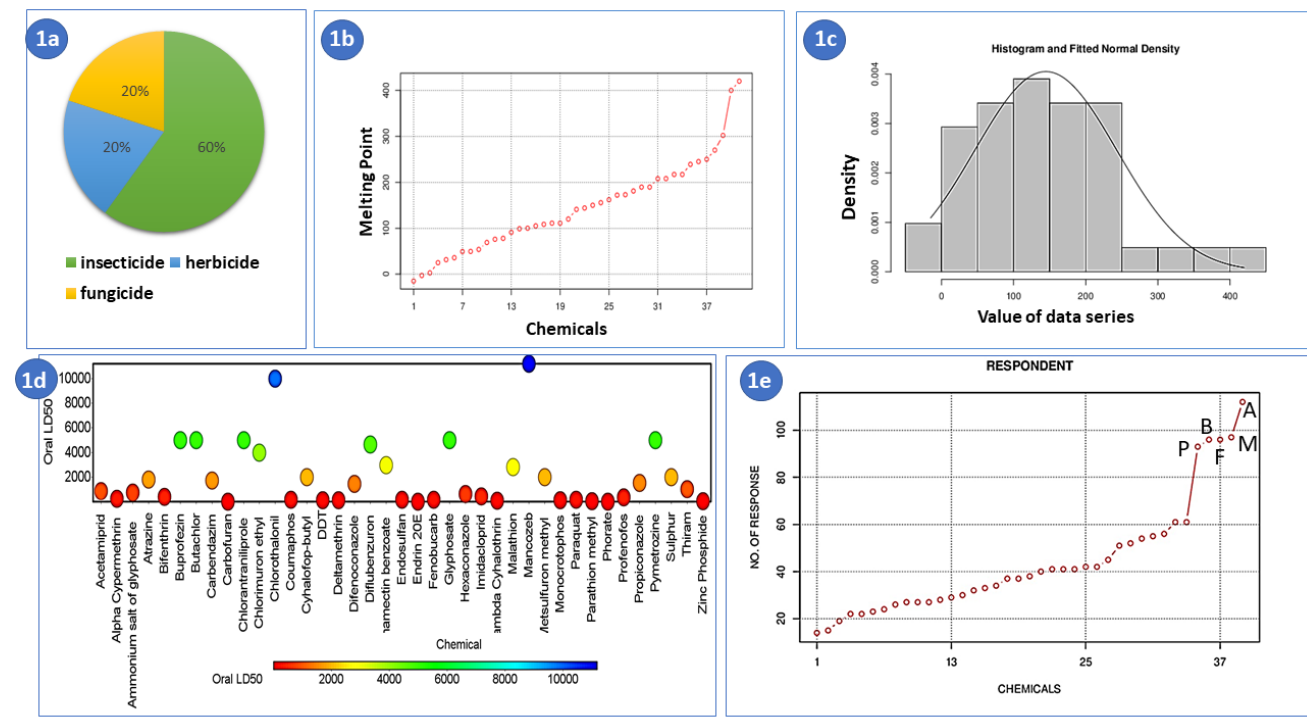

Figure 2. Analysis of different parameters of the 39 chemicals used in Eastern India. 1a) Percentage of chemicals classified in different categories; $1 \mathrm{~b}$ ) Melting point analysis of the different chemicals, the melting points ranges from -15 to $420^{\circ} \mathrm{C}$; $1 \mathrm{C}$ ) Statistical distribution (fitted normal density) obtained from the melting point analysis creates three quartiles; 1d) Comparison of oral LD50 values of 39 chemicals, red means extremely hazardous and blue means non-hazardous; 1e) Plot of chemicals against number of respondents show five chemicals are mostly used and they are presented in the diagram as A (alpha-cypermethrin), M (mancozeb), F (fenobucarb), B (Buprofezin) and P (phorate).

pharmacophoric similarity.

\section{Selection of proteins for docking}

In this study, Swiss TargetPrediction was used to find the best possible targets for the selected five chemicals. Three different proteins including 1 e66 acetylcholinesterase, 13pk phosphoglycerate kinase, and 121p GTPase HRas were predicted as the common targets of these chemicals. The best resolutions of these proteins were selected for docking purpose where 1e66 TcAChE, 13pk TbPGK, and 121p GTPase HRas have resolutions of 2.100, 2.500, and 1.540 respectively. To ensure the minimum structural similarity among the selected proteins, for better understanding of the binding interactions, sequence alignment studies were done. Between 1e66 TcAChE and 13pk TbPGK, identities were found to be $1.84 \%$ and $2.41 \%$, respectively, whereas similarities were seen to be $2.39 \%$ and $3.13 \%$, respectively. In the case of 1 e66 TcAChE and 121p GTPase HRas, the similarities and identities were evaluated as $2.39 \%$ (1e66 TcAChE), 7.83\% (121p GTPase HRas), 1.66\% (1e66 TcAChE), and 5.42\% (121p GTPase HRas). When the sequences of 121p GTPase HRas and 13pk TbPGK were compared, they showed 14.46\% (121p GTPase HRas) and 5.78\% (13pk TbPGK) similarities and identity scores of $8.43 \%$ (121p GTPase HRas) and 3.37\% (13pk TbPGK).

\section{Analysis of docking studies}

For the docking study, the five chemicals reported as frequently used in the survey, were selected (Figure 2e). These chemicals (structure and IUPAC nomenclature are given in Figure 4 were docked with three different proteins including 121p GTPase HRas, Torpedo acetylcholinesterase, trypanosome phosphoglycerate kinase. It is worth mentioning that only the best docking chemical pose were studied to analyze the most stable protein-ligand interactions.

In Torpedo acetylcholinesterase, all the five chemicals were docked within the polypeptide sequence, starting from glutamine 66 and ending at tyrosine 439 (Table 2, Figure 5). Alpha cypermethrin shows the highest binding affinity towards AChE with a docking score of -11.2, followed by buprofezin (-8.9) and fenobucarb (-8.3). The most significant fact is that the binding site of AChE contains many aromatic amino acid residues that interact with the aromatic rings present in alpha-cypermethrin, buprofezin, fenobucarb, and also take part in other attractive interactions that contribute to protein-ligand binding (Figure 5). However, phorate and mancozeb show a slightly weaker binding affinity towards the active site of AChE, and that maybe because of the absence of aromatic rings. Moreover, it is also evident that conventional $\mathrm{H}$-bonds do not contribute predominantly to the case of AChE-selected chemical interactions.

Docking trypanosome phosphoglycerate kinase with all the subjects of interest (Figure 6) reveals that this protein shows propinquity towards alpha cypermethrin $(-8.9)$ and buprofezin (-8.7). Whilst fenobucarb, phorate, and mancozeb bind to PGK proficiently with binding scores of $-6.7,-4.8$, and -4.0 , respectively. The active peptide sequence of PGK is outstretched from glycine 213 to glutamic acid 341. Ala 238, Tyr 241, Gly 338, and Glu 341 are the residues that interact with the chemicals by forming H-bonds whereas, Phe 290 is involved in pi-stacking 

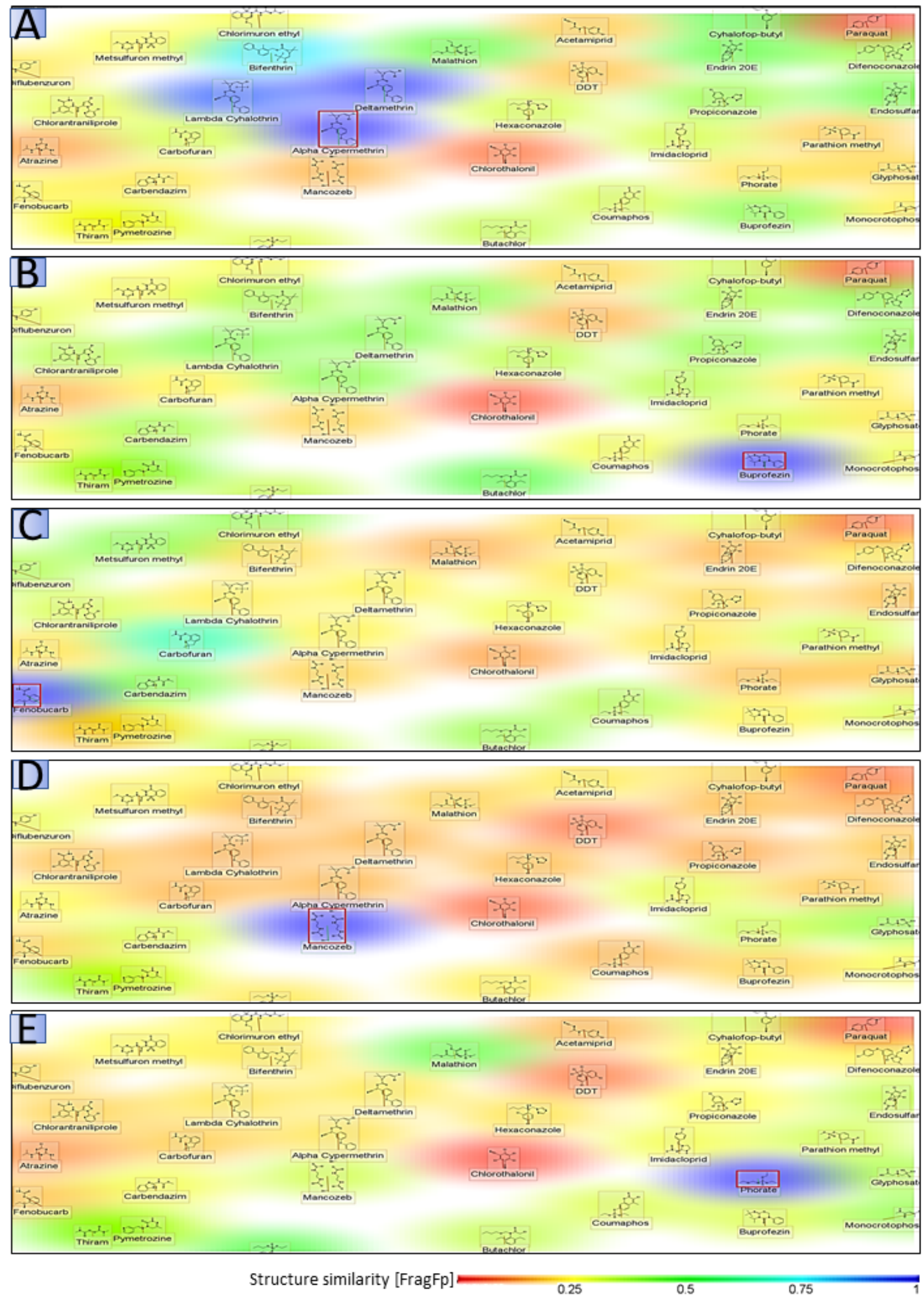

Figure 3. Chemical similarity analysis of the cidal chemicals used in Eastern India with respect to the five seed molecules. 2A) Similarity analysis with respect to alpha-cypermethrin (shown in red box); 2B) Similarity analysis with respect to buprofezin (shown in red box); 2C) Similarity analysis with respect to fenobucarb (shown in red box); 2D) Similarity analysis with respect to mancozeb; 2E) Similarity analysis with respect to phorate (shown in red box); structural similarity [FragFp] of 0 to 1 represents poor to best similarities. 


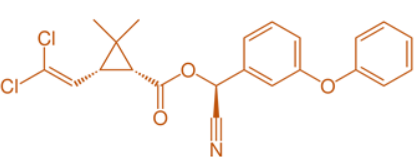

Alpha-cypermethrin IUPAC Name: [(S)-cyano-(3-phenoxyphenyl)methy ] $(1 R, 3 R)$-3-(2,2-dichloroethenyl)-2,2dimethylcyclopropane-1-carboxylate

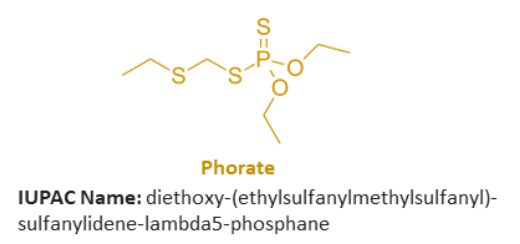

IUPAC Name: diethoxy-(ethylsulfanylmethylsulfanyl)sulfanylidene-lambda5-phosphane

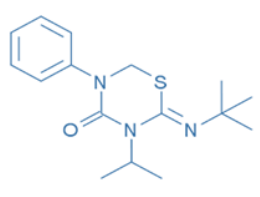

Buprofezin PAC Name: 2-tert-butylimino-5phenyl-3-propan-2-yl-1,3,5thiadiazinan-4-one

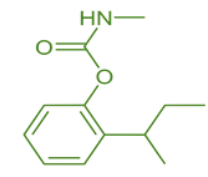

Fenobucarb

: (2-butan-2ylphenyl) $\mathrm{N}$-methylcarbamate

$$
{ }_{S}{ }_{S}^{H}
$$

IUPAC Name: zinc; manganese(2+); $\mathrm{N}$-[2-

(sulfidocarbothioylamino)ethyl]carbamodithioate

Figure 4. Structure and IUPAC nomenclature of the chemicals selected for docking purpose.
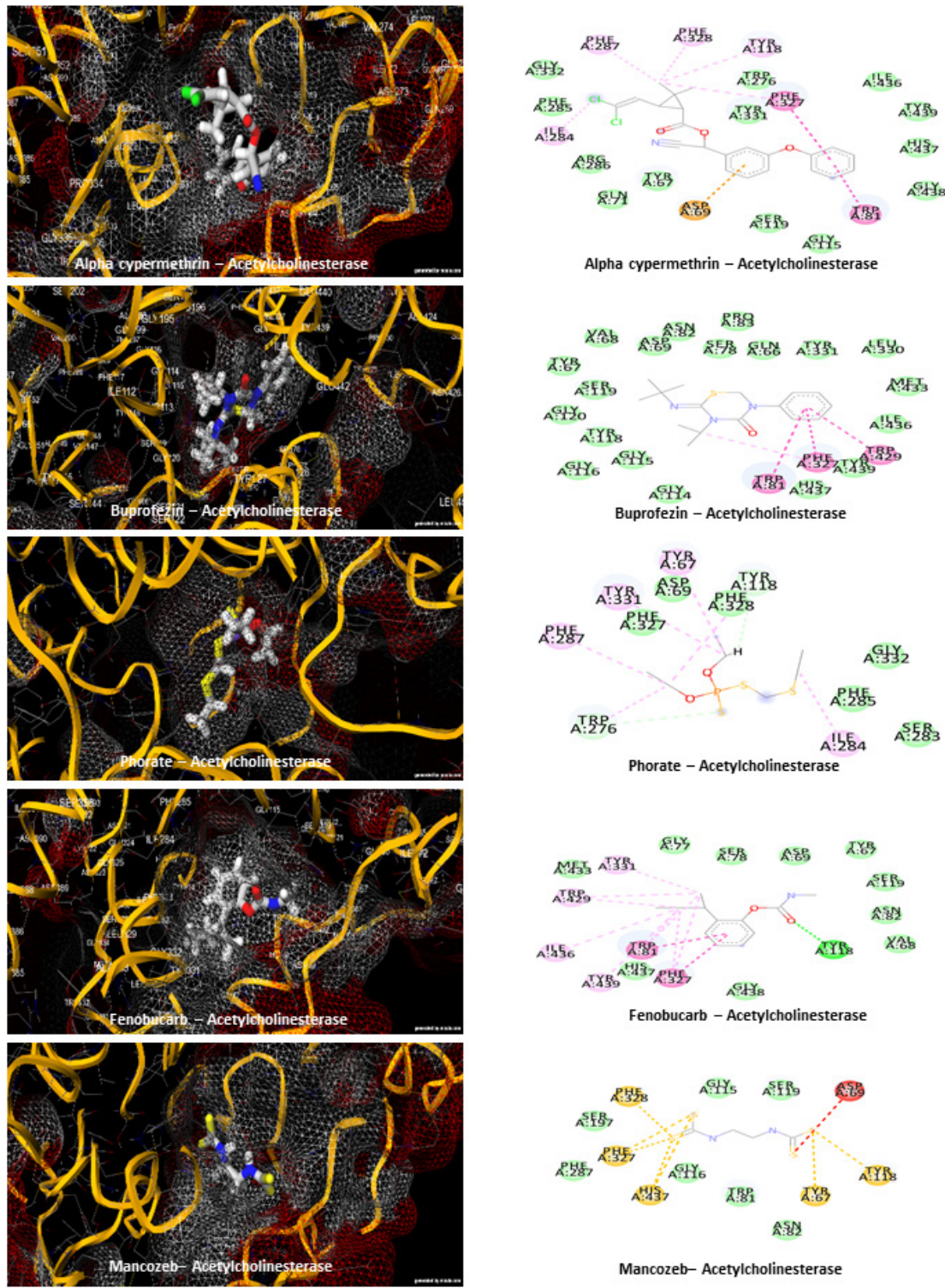

Mancozeb- Acetylcholinesterase

Figure 5. Docking of the five selected chemicals with acetylcholinesterase. The images on the left side are the screenshots of the docking results obtained from mcule. The images on the right side show the $2 \mathrm{D}$ view of the interactions between the ligand and binding site of the protein. 
Table 2. Docking parameters of the docked complexes obtained from the docking of the selected proteins with the selected chemicals along with the number of different types of binding interactions

\begin{tabular}{|c|c|c|c|c|c|c|}
\hline Docked complex & $\begin{array}{l}\text { Best } \\
\text { docking } \\
\text { score }\end{array}$ & $\begin{array}{c}\text { No. of } \\
\text { conventional } \\
\text { H-bond }\end{array}$ & $\begin{array}{l}\text { Van der } \\
\text { waals int }\end{array}$ & Pi-stacked int & Pi-alkyl int & $\begin{array}{c}\text { Attractive charge } \\
\text { int }\end{array}$ \\
\hline Alpha-Hras & -8.4 & 0 & 19 & 1 & 4 & 0 \\
\hline Bupro-Hras & -7.6 & 1 & 16 & 1 & 2 & 0 \\
\hline Phorate-Hras & -4.2 & 3 & 14 & 0 & 2 & 0 \\
\hline Feno-Hras & -6.2 & 1 & 9 & 1 & 3 & 0 \\
\hline Manco-Hras & -3.9 & 3 & 10 & 0 & 0 & 1 \\
\hline Alpha-AChE & -11.2 & 0 & 13 & 2 & 4 & 0 \\
\hline Bupro-AChE & -8.9 & 0 & 19 & 3 & 1 & 0 \\
\hline Phorate-AChE & -5.3 & 0 & 6 & 0 & 4 & 0 \\
\hline Feno-Ache & -8.3 & 1 & 10 & 2 & 4 & 0 \\
\hline Manco-AChE & -4.2 & 0 & 7 & 0 & 0 & 5 \\
\hline Alpha-PGK & -8.9 & 2 & 13 & 1 & 2 & 0 \\
\hline Bupro-PGK & -8.7 & 1 & 9 & 1 & 4 & 0 \\
\hline Phorate-PGK & -4.8 & 0 & 13 & 0 & 4 & 1 \\
\hline Feno-PGK & -6.7 & 1 & 10 & 1 & 3 & 0 \\
\hline Manco-PGK & -4 & 2 & 11 & 0 & 0 & 2 \\
\hline
\end{tabular}

Alpha, alpha-cypermethrin; bupro, buprofezin; Feno, fenobucarb; Manco, mancozeb; HRas, 121p GTPase HRas; AChE, 1e66 Torpedo californica acetylcholinesterase; PGK, 13pk trypanosoma brucei phosphoglycerate kinase; Int, interactions.

interaction; however, only with alpha-cypermethrin.

121p GTPase HRas is a short 166 residue protein that can bind to all the studied five chemicals (Figure 7). A similar order of binding capacity among the chemicals can be seen here as alpha cypermethrin $(-8.4)>$ buprofezin $(-7.6)>$ fenobucarb $(-6.2)>$ phorate $(-4.2)>$ mancozeb (-3.9). In contrast to AChE or PGK, GTPase HRas active site shows a higher number of conventional H-bonding interactions with the ligands. Despite three hydrogen bonding interactions with the protein in each case, both phorate and mancozeb showed poor binding affinity.

\section{Discussion}

Toxicity imposed by different kinds of pesticides can be either acute or chronic (25). The harmful effects caused by a single exposure through any route of entry are termed acute effects. Any harmful effects caused by small doses repeated over a while are termed chronic effects. Recently, several studies have established a link between pesticides exposure and the incidences of human chronic diseases like cancer (childhood and adult brain cancer, renal cancer, lymphocytic leukemia, prostrate cancer in childhood and adults) (26-31), neurodegenerative diseases including Parkinson's disease (32) and Alzheimer's disease (33), cardio-vascular disease including coronary artery disease (34), type 2 diabetes (35), reproductive disorders $(36,37)$, birth defects $(38,39)$, hormonal imbalances (40), respiratory diseases (asthma, chronic obstructive pulmonary disease) $(41,42)$, etc. Conversely, some biochemical alterations may not necessarily lead to clinically recognizable symptoms, although all the biochemical responses can be used as markers of exposure or effect (43).

Consistent with these reports, the present study also revealed a considerable number of subjects suffering from these deadly diseases. The most disturbing part of the survey reveals that almost $12 \%$ of the respondents aged above 40 years had cancer. Additionally, $11 \%$ and $7 \%$ of farmers suffer from neurodegenerative diseases and cardiovascular diseases, respectively. 10 farmer families in Bankura district had girls who assisted in field, reported to have hormonal imbalance and irregular menstruation. However, the fact that the diseases are caused only by the atrocious effects of the pesticides up in the air; there remains a high possibility of being so. the pesticides is uncertain, but there is a high possibility that this might be the cause.

The chemicals that are spreading their nocuous effects on the farmers of Eastern India can be categorized into different toxicity levels, where 28 of them can leave their conspicuous rough marks on human life. Almost 54\% of the chemicals are irritant, $41 \%$ are tumorigenic, $46 \%$ are mutagenic, and $51 \%$ can affect the victims' reproductive health (Figure 8). Fifteen chemicals are known to cause only mild symptoms and are not involved in any nasty functions (Figure 8).

Among all these chemicals, five chemicals predominantly used in Eastern India were selected for further studies. Melting point data analysis supports the selection as these chemicals have different melting points allowing to study a wide range of chemicals since the melting point of chemicals depends on various structural aspects. Cidal chemicals can be classified according to their structural bases as organochlorines, organophosphates, 

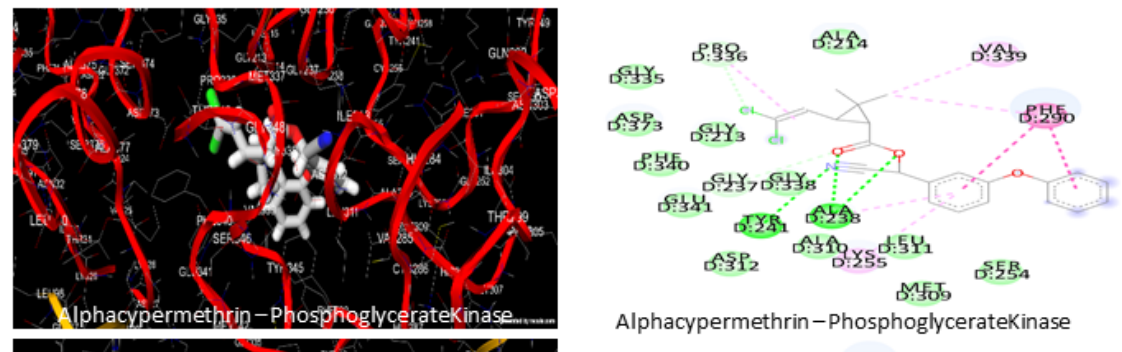

Alphacypermethrin-PhosphoglycerateKinase
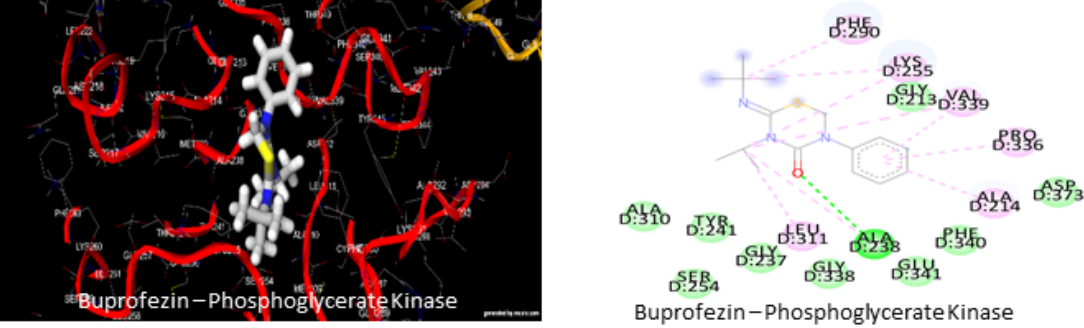

Buprofezin-Phosphoglycerate Kinase
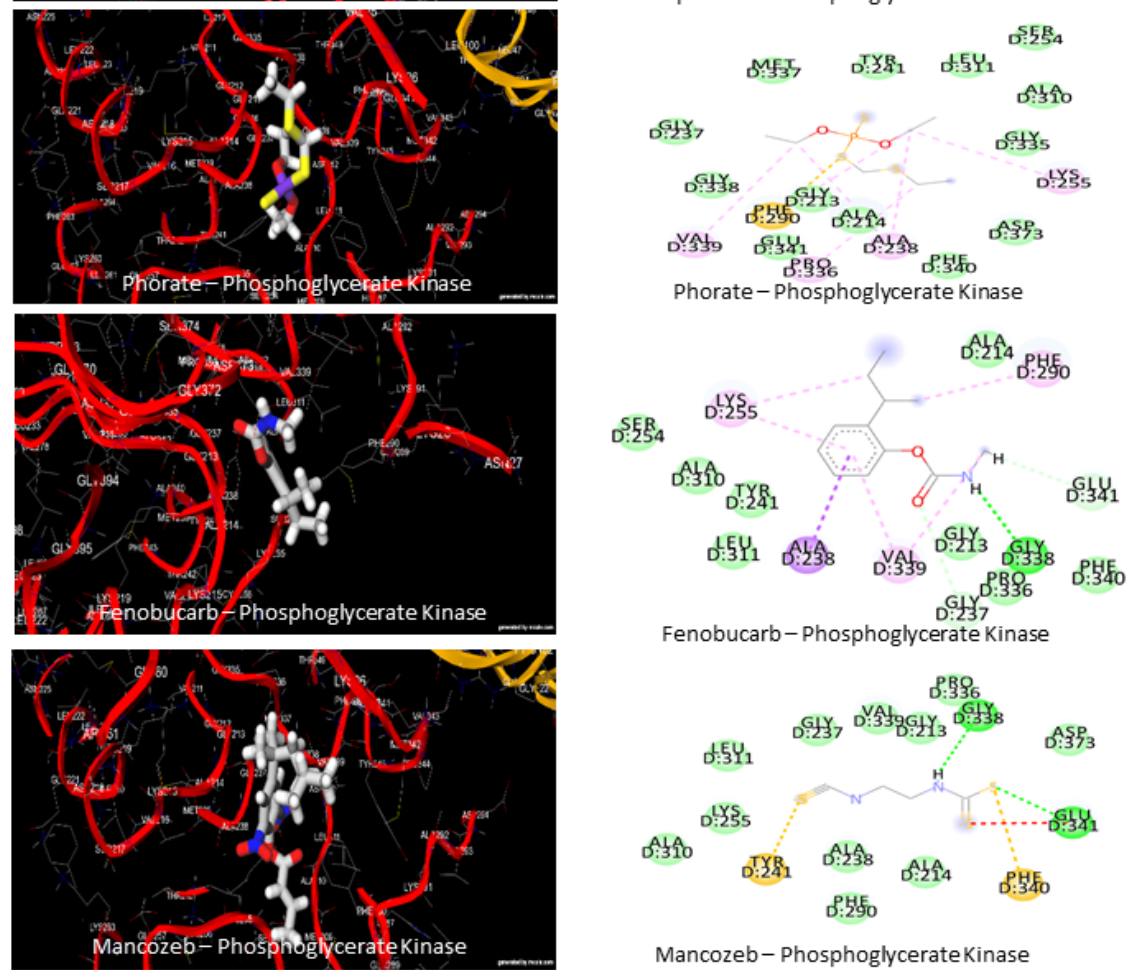

Mancozeb-PhosphoglycerateKinase

Figure 6. Docking of the five selected chemicals with phosphoglycerate kinase. The images on the left side are the screenshots of the docking results obtained from mcule. The images on the right side show the $2 \mathrm{D}$ view of the interactions between the ligand and binding site of the protein.

carbamates, and pyrethroids (44). Among the selected chemicals, alpha-cypermethrin is a pyrethroid, phorate is an organophosphate, buprofezin is a thiadiazinane, and the rest two are carbamates. Fenobucarb is a carbamate, whereas mancozeb is a dithiocarbamate (carbamate analog having both oxygens replaced by sulphur atom). The selection of this wide range of chemical structure enabled us to do further research with only five chemicals instead of all the 39 chemicals. Theoretically, all the pyrethroids should have some chemical similarities among themselves. The case would be the same with all the carbamates or the organophosphates. The presence of analogous groups or atoms in a particular class of chemicals may enable them to show similar interactions with a particular binding molecule. To validate this supposition, a chemical similarity analysis was performed with five seed molecules only to find out that all the chemicals except three of them (chlorothalonil, paraquat, and DDT), are structurally related to these five molecules of preference. Thus, it can be expected that the binding property shown by the other molecules will be somewhat similar to these five molecules.

This study aimed not only to evaluate the effect of pesticide poisoning in farmers of Eastern India but also to catch on a plausible solution. As it is evident that inhalation of pesticides causes paramount damage to a 

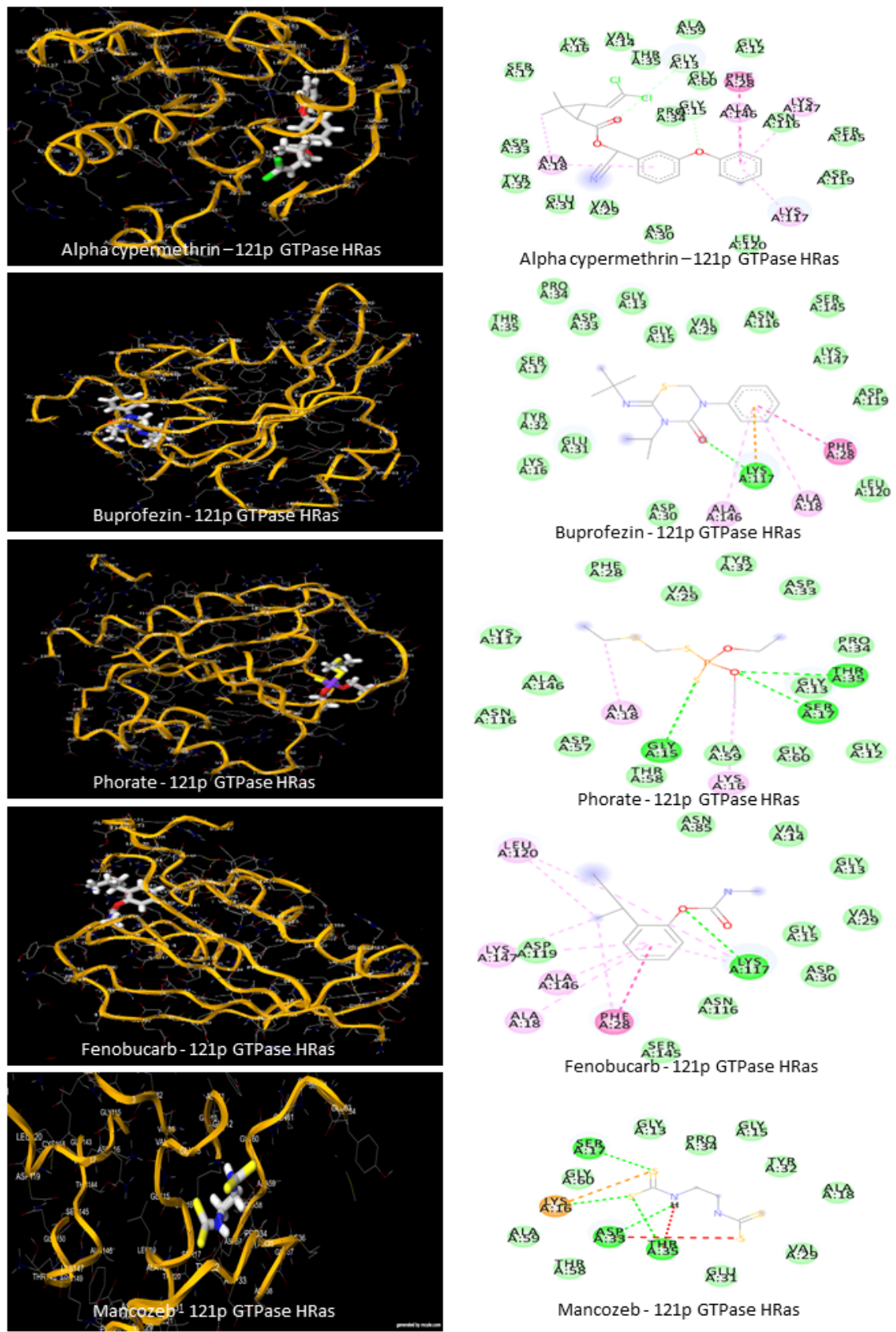

Mancozeb - 121p GTPase HRas

Figure 7. Docking of the five selected chemicals with GTPase HRas. The images on the left side are the screenshots of the docking results obtained from mcule. The images on the right side show the 2D view of interactions between the ligand and binding site of the protein.

farmer's health, the first priority was finding a suitable binding agent that can trap these foul chemicals. Despite the fact that many such technologies are present, a peptide-based agent is still a better way for this purpose. The adsorption techniques have been frequently used for removing organic and inorganic pollutants since its discovery in 1940. Out of the natural materials, proteins are prospective materials that are used as adsorbents owing to many different types of functional groups that reside on the side chains of amino acid residues. They are also advantageous due to their biodegradability. Peptides trap different organo-chemicals and metal ions by virtue of their physisorption and chemisorption abilities (45).
Physisorption directs the chemicals to be trapped in a porous network on the proteins surface while the peptide bonds and the functional groups on the side chains offer active sites for chemisorption of the approaching chemicals (46).

Based on the target prediction using selected chemicals, three proteins including acetylcholinesterase, GTPase HRas, and phosphoglycerate kinase came up as the typical targets for all the chemicals. In this study, Torpedo $1 \mathrm{e} 66$ acetylcholinesterase, trypanosoma $13 \mathrm{pk}$ phosphoglycerate kinase, and 121p GTPase HRas were selected considering their resolution. Comparison of protein sequence confirmed a little similarity and identity among the 

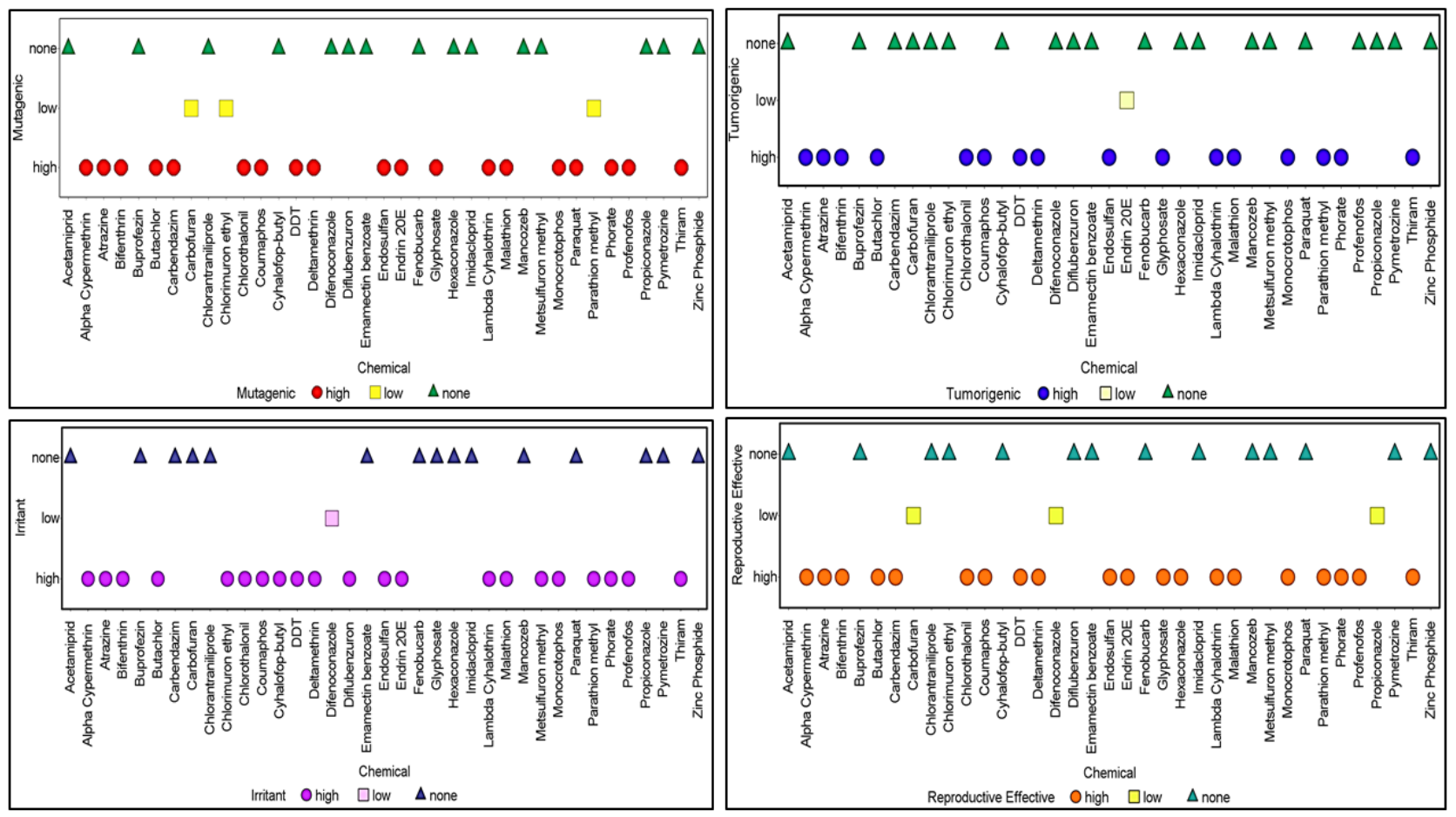

Figure 8. The bio-activity comparison of the cidal chemicals found to be extensively used in Eastern India. This image shows mutagenic (upper left), tumorigenic (upper right), irritant (lower left), and effective reproductive (lower right) characteristics of the chemicals.

selected peptide sequences. All the selected proteins were evaluated based on their specific docking features obtained after docking with the selected chemicals. The following aspects were found from the docking results (Figure 9), and these aspects can be useful for the proposed purpose:

1. The affinity of all the chemicals towards the different proteins follows the order: 1e66 TcAChE > 13pk TbPGK > 121p GTPHR.

2. The binding affinity of the chemicals follows the order: alpha-cypermethrin > buprofezin > fenobucarb $>$ phorate $>$ mancozeb and this is true for all the selected proteins.

To find out the reason behind these results, a comparative analysis of the protein structures and different types of

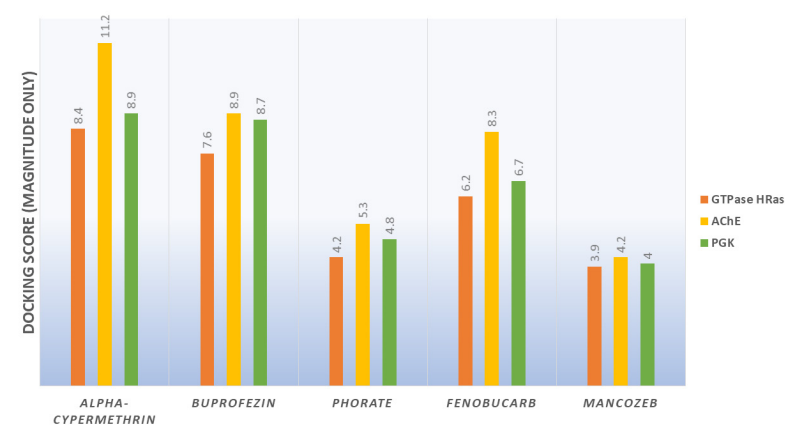

Figure 9. Comparison of the binding affinity (from docking score) of the five chemicals when bound to three different proteins used in this study. (Only the magnitudes are taken, i.e. the -ve sign of energy is not used in data plotting). interactions was carried out. TcAChE is a protein with more than 500 amino acid residues having 12 mixed $\beta$-sheet surrounded by $14 \alpha$-helices (47). This protein's active site is fringed by 14 aromatic amino acid residues that contribute to the greatest extent of adsorbing the chemicals within it. 13 pk TbPGK is a 415 -residue protein having two equal-sized domains, each made of 6-stranded parallel $\beta$-sheet and linked by two $\alpha$-helices (48). It uses hydrogen bonding ability as well as its aromatic amino acid residues to bind the chemicals. 121p GTPHR comprises six $\beta$-sheet structures along with five $\alpha$-helices (49). The G-domain of its two domains contains 166 amino acid residues, and it participates in binding with the chemicals using $\mathrm{H}$-bonding ability of its amino acid residues, as is shown in the study.

1 e66 TcAChE as well as its substructure can be used as the adsorbent protein. The presence of many aromatic amino acid residues and the remarkable electrostatic characteristic of AChE makes it a great candidate for this purpose. The hydrophobicity of the aromatic gorge present in AChE can result in low dielectric constant in the gorge region that can help inceptive adsorption of the chemicals and further diffusion of the chemicals to the high-affinity sites (50). TcAChE has a very high dipole moment that acts nearly along the axis of the aromatic gorge. This dipole moment may help to induce the positively charged or electron-deficient substances to bind (51). Along the aromatic gorge, a potential gradient is active, which may further help the chemicals deep into the gorge the chemicals to glide deep into the gorge (52). 
It is also evident that a weakly hydrated environment favors $\pi$ - cation or $\pi$-stacking interactions between the enzyme and its substrate acetylcholine (53). This is an important point to be noted since the cidal chemicals are generally sprayed as an aqueous solution that will create the hydrated environs suitable for binding with protein. Another add-on to the astonishing structural facet of TcAChE is its prodigious inflexibility (54). That means binding of a ligand will not change its binding efficiency towards the next approaching ligand. This feature is very much crucial for the spatiotemporal effectiveness of the trapping agent.

The random coil structure is more effective in absorption than its native structure because of a relatively looser structure and hence more surface area that opens up more sites for absorption $(55,56)$. Chaotropic agents can be used for obtaining a random coil structure by disrupting the bonding network acting in the $3 \mathrm{D}$-structure of the protein (57).

Regeneration of sorbents should be a pertinent feature for a potential adsorbent of commercial importance. Typically, mesh-shaped fabrics are ideal for uniform and reproducible properties compared to loose fibrous or particulate sorbents, which enable them to be cleaned and reused. AChE contains a large number of ionizable groups, and its isoelectric point is 5.6. This characteristic of AChE influences the absorption and desorption characteristics of the absorbent systems.

This study shows that not a particular type of interaction plays a role in binding (Figure 10). However, it is also evident that high docking scores in the study are accompanied by pi-stacking interactions between aromatic rings of the aromatic amino acid residues and the binding molecules. The best docking score for acetylcholinesterase can be correlated with the contribution of a large number
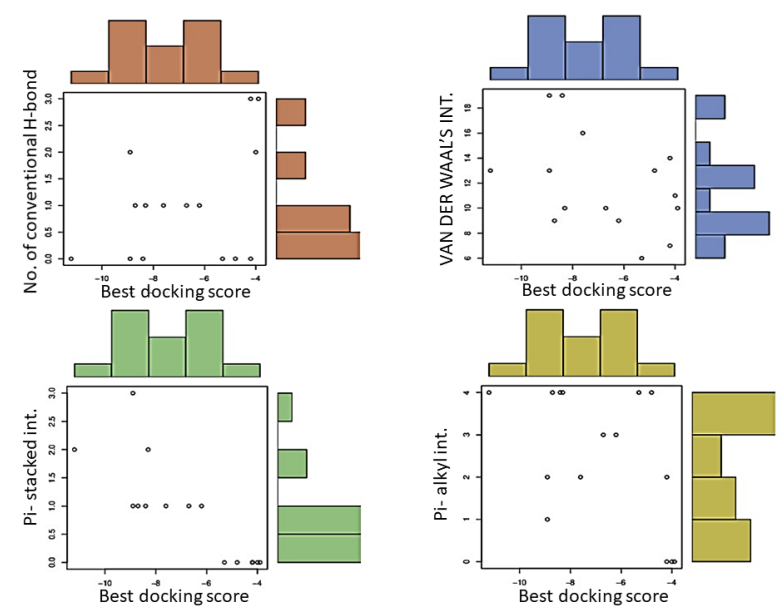

Figure 10. Scattered plot of different types of interactions against the docking scores. In this study, number of conventional $\mathrm{H}$-bonds (upper left), number of Van der Waals interactions (upper right), number of pi-stacking interactions (lower left) and number of pi-alkyl interactions (lower right) are plotted against the corresponding docking score. of interacting phenyl rings of aromatic amino acid residues. This stability can be validated by considering the Pi-stacking interactions between ligand and peptide phenyl rings, increasing pi-donor hydrogen bonds, and pielectronegative atom interactions. Alpha-cypermethrin, buprofezin, and fenobucarb contain aromatic rings in their structure and as seen in phorate, carbamate part of mancozeb contains no phenyl ring, as a result, they show the least docking score. The presence of $\mathrm{H}$-bonding interaction always does not guarantee a high docking score (58) as it happened in this study also, but it certainly plays a significant role in a close-grained binding (59). The presence of $\mathrm{H}$-bond donors and acceptors in large numbers can increase the binding affinity significantly. So, the attentive substitution of electron-donating and/ or electron-withdrawing groups in amino acid side chains can be a useful aspect for modification while using $\mathrm{AChE}$ as a binding agent without the deliberation of the structural stability.

However, certain conditions are modulated to amplify the stability of the protein while it is used as a binding agent. For example, proteins maintain a denaturation temperature above which their $3 \mathrm{D}$ structure is disintegrated, and the same happens with altering $\mathrm{pH}$ values. This can thwart the long-term use of the protein as a binding agent in commercial purpose. To increase the thermostability or the stability in slightly acidic or basic conditions, various structural and sequence factors should be taken into accounts, such as helical content, H-bonding, salt-bridges, polar surface area, and other factors which contribute to the thermophilicity of some proteins $(60,61)$. The efficiency of chemical removal, which indicates if the adsorbent is reusable or not, depends on the specific surface area, the activity of absorbents, solution $\mathrm{pH}$, contact time, temperature, presence of other chemicals and their concentrations, and the chemical nature of the cidal chemicals (62). Therefore, further in-silico and invitro studies are required for an accurate understanding of the physical and chemical properties.

\section{Conclusion}

The most undervalued professionals who are the main reason for humankind's thriving, the farmers of our land, have been long-suffering in silence by the exposure to the high levels of dangerous agrochemicals. The inexorably agonizing consequences of such negligence towards agrochemical abuse have destroyed millions of innocent people. This baseline survey explored the patterns of usage and impact of the most frequently used pesticides, insecticides, herbicides, etc., in the Eastern parts of India and assessed the type of threats they induct. Alpha cypermethrin, buprofezin, fenobucarb, phorate, and mancozeb were found to be the most frequently used perilous agrochemicals.

These chemicals were used to formulate and hypothesize a preventive measure employing an in-silico methodology. 
Due to the abundant presence of aromatic amino acids at the docking sites, the docking studies have revealed that acetylcholinesterase has the promising potential of becoming a commercially successful absorbent that can find its application as a trapping agent for cidal chemicals. However, the results are preliminary and certainly need experimental justifications to concretize the validity of the claims presented in this research.

\section{Acknowledgments}

This paper and the research behind it would not have been possible without the exceptional national research venture planned by CSIR-North East Institute of Science and Technology, Jorhat, Assam. Authors would like to thank Dr. N. Shastri, Director, NEIST and Dr. Prasenjit Manna, for their generosity and consistent belief in the team constituted for Summer Research Training Program. They also thank ICRISAT, BBSR; DDA, Sambalpur; Bidhan Chandra Krishi Vishwavidyalaya, Kalyani, Nadia; for their continuous support during the baseline survey. And special thanks to authors' colleagues from different labs for helpful insights and discussions.

\section{Ethical issues}

Before conducting the present investigation, informed consent was obtained from all participants who were interviewed to understand the usage and impacts of the agrochemicals. This entire work was carried out as the project for CSIR-North East Institute of Science and Technology, Jorhat, Assam, India. No bioethical issues were involved in the present work. The authors certify that this manuscript is the original work of the authors, all data collected during the study are presented in the manuscript, and no data from the study has been or will be published separately.

\section{Competing interests}

The authors declare that they have no conflict of interests.

\section{Authors' contributions}

All contributing authors participated equally in the data collection, analysis, and interpretation. All authors critically reviewed, refined, and approved the manuscript.

\section{References}

1. Wagh RR, Dongre A. Agricultural sector: status, challenges and it's role in Indian economy. Journal of Commerce and Management Thought 2016; 7(2):209. doi: 10.5958/0976478X.2016.00014.8.

2. Shetty PK, Sabitha M. Economic and Ecological Externalities of Pesticide Use in India. Dordrecht: Springer; 2009. p. 113-29.

3. Aktar MW, Sengupta D, Chowdhury A. Impact of pesticides use in agriculture: their benefits and hazards. Interdiscip Toxicol 2009; 2(1): 1-12. doi: 10.2478/v10102-009-0001-7.

4. Devi PI, Thomas J, Raju RK. Pesticide consumption in India: a spatiotemporal analysis. Agricultural Economics
Research Review 2017; 30(1): 163-72. doi: 10.5958/09740279.2017.00015.5.

5. Bertolote JM, Fleischmann A, Eddleston M, Gunnell D. Deaths from pesticide poisoning: A global response. $\mathrm{Br} \mathrm{J}$ Psychiatry 2006; 189: 201-3. doi: 10.1192/bjp.bp.105.020834.

6. WHO. The WHO STEPwise Approach to Chronic Disease Risk Factor Surveillance. USA: WHO; 2005.

7. Lushchak VI, Matviishyn TM, Husak VV, Storey JM, Storey KB. Pesticide toxicity: a mechanistic approach. EXCLI J 2018; 17: 1101-36. doi: 10.17179/excli2018-1710.

8. Costa LG. Toxic Effects of Pesticides. In: Klaassen CD. Casarett and Doull's Toxicology. 8th ed. China: McGrawHill; 2008.

9. Dedek W. Routes of entry and wards during exposure to pesticides. Studies in Environmental Science 1982; 18: 187 97. doi: 10.1016/S0166-1116(09)70046-9.

10. Colovic MB, Krstic DZ, Lazarevic-Pasti TD, Bondzic AM, Vasic VM. acetylcholinesterase inhibitors: pharmacology and toxicology. Curr Neuropharmacol 2013; 11(3): 315-35. doi: 10.2174/1570159X11311030006.

11. Vidair CA. Age dependence of organophosphate and carbamate neurotoxicity in the postnatal rat: Extrapolation to the human. Toxicol Appl Pharmacol 2004; 196(2): 287302. doi: 10.1016/j.taap.2003.12.016.

12. Jayaraj R, Megha P, Sreedev P. Organochlorine pesticides, their toxic effects on living organisms and their fate in the environment. Interdiscip Toxicol 2016; 9(3-4): 90-100. doi: 10.1515/intox-2016-0012.

13. Hernández AF, Parrón T, Tsatsakis AM, Requena M, Alarcón R, López-Guarnido O. Toxic effects of pesticide mixtures at a molecular level: their relevance to human health. Toxicology 2013; 307: 136-45. doi: 10.1016/j. tox.2012.06.009.

14. Qiao J, Du Y, Yu J, Guo J. MicroRNAs as potential biomarkers of insecticide exposure: a review. Chem Res Toxicol 2019; 32(11): 2169-81. doi: 10.1021/acs.chemrestox.9b00236.

15. Ye J, Zhao M, Niu L, Liu W. Enantioselective environmental toxicology of chiral pesticides. Chem Res Toxicol 2015; 28(3): 325-38. doi: 10.1021/tx500481n.

16. Damalas CA, Eleftherohorinos IG. Pesticide exposure, safety issues, and risk assessment indicators. Int J Environ Res Public Health 2011; 8(5): 1402-19. doi: 10.3390/ ijerph8051402.

17. Chakraborty S, Mukherjee S, Roychoudhury S, Siddique S, Lahiri T, Ray MR. Chronic exposures to cholinesteraseinhibiting pesticides adversely affect respiratory health of agricultural workers in India. J Occup Health 2009; 51(6): 488-97. doi: 10.1539/joh.19070.

18. Ghahrchi M, Bazrafshan E, Badan BA, Shahamat YD, Gohari F. Application of heterogeneous catalytic ozonation process for treatment of high toxic effluent from a pesticide manufacturing plant. Environ Health Eng Manag 2020; 7(2): 79-88. doi: 10.34172/EHEM.2020.10.

19. Kim S, Chen J, Cheng T, Gindulyte A, He J, He S, et al. PubChem 2019 update: Improved access to chemical data. Nucleic Acids Res 2019; 47(D1): D1102-9. doi: 10.1093/ nar/gky1033.

20. Wessa. Free Statistics and Forecasting Software. [cited 2020 Oct 12] Available from: http://www.wessa.net.

21. Backman TW, Cao Y, Girke T. ChemMine tools: an online service for analyzing and clustering small molecules. 
Nucleic Acids Res 2011; 39(Web Server issue): W486-91. doi: $10.1093 / \mathrm{nar} / \mathrm{gkr} 320$.

22. Sander T, Freyss J, von Korff M, Rufener C. DataWarrior: an open-source program for chemistry aware data visualization and analysis. J Chem Inf Model 2015; 55(2): 460-73. doi: 10.1021/ci500588j.

23. Gfeller D, Michielin O, Zoete V. Shaping the interaction landscape of bioactive molecules. Bioinformatics 2013; 29(23): 3073-9. doi: 10.1093/bioinformatics/btt540.

24. Smith TF, Waterman MS. Identification of common molecular subsequences. J Mol Biol 1981; 147(1): 195-7. doi: 10.1016/0022-2836(81)90087-5.

25. Damalas CA, Koutroubas SD. Farmers' exposure to pesticides: Toxicity types and ways of prevention. Toxics 2016; 4(1):1. doi: 10.3390/toxics4010001.

26. Cocco P, Satta G, Dubois S, Pili C, Pilleri M, Zucca M, et al. Lymphoma risk and occupational exposure to pesticides: Results of the Epilymph study. Occup Environ Med 2013; 70(2): 91-8. doi: 10.1136/oemed-2012-100845.

27. Band PR, Abanto Z, Bert J, Lang B, Fang R, Gallagher RP, et al. Prostate cancer risk and exposure to pesticides in British Columbia farmers. Prostate 2011; 71(2): 168-83. doi: 10.1002/pros.21232.

28. $\mathrm{Xu} \mathrm{X}$, Dailey $\mathrm{AB}$, Talbott EO, Ilacqua VA, Kearney G, Asal NR. Associations of serum concentrations of organochlorine pesticides with breast cancer and prostate cancer in U.S. adults. Environ Health Perspect 2010; 118(1): 60-6. doi: 10.1289/ehp.0900919.

29. Heck JE, Charbotel B, Moore LE, Karami S, Zaridze DG, Matveev V, et al. Occupation and renal cell cancer in Central and Eastern Europe. Occup Environ Med 2010; 67(1): 47-53. doi: 10.1136/oem.2009.046250.

30. Shim YK, Miynarek SP, van Wijngaarden E. Parental exposure to pesticides and childhood Brain cancer: U.S. Atlantic coast childhood brain cancer study. Environ Health Perspect; 117(6): 1002-6. doi: 10.1289/ehp.0800209.

31. Lee WJ, Colt JS, Heineman EF, McComb R, Weisenburger DD, Lijinsky W, et al. Agricultural pesticide use and risk of glioma in Nebraska, United States. Occup Environ Med 2005; 62(11): 786-92. doi: 10.1136/oem.2005.020230.

32. Elbaz A, Clavel J, Rathouz PJ, Moisan F, Galanaud JP, Delemotte B, et al. Professional exposure to pesticides and Parkinson disease. Ann Neurol 2009; 66(4): 494-504. doi: 10.1002/ana.21717.

33. Hayden KM, Norton MC, Darcey D, Østbye T, Zandi PP, Breitner JC, et al. Occupational exposure to pesticides increases the risk of incident AD: The Cache County study. Neurology 2010; 74(19): 1524-30. doi: 10.1212/ WNL.0b013e3181dd4423.

34. Andersen HR, Wohlfahrt-Veje C, Dalgård C, Christiansen L, Main KM, Nellemann C, et al. Paraoxonase 1 polymorphism and prenatal pesticide exposure associated with adverse cardiovascular risk profiles at school age. PloS One 2012; 7(5): e36830. doi: 10.1371/journal.pone.0036830.

35. Son HK, Kim SA, Kang JH, Chang YS, Park SK, Lee SK, et al. Strong associations between low-dose organochlorine pesticides and type 2 diabetes in Korea. Environ Int 2010; 36(5): 410-4. doi: 10.1016/j.envint.2010.02.012.

36. Petrelli G, Mantovani A. Environmental risk factors and male fertility and reproduction. Contraception 2002; 65(4): 297-300. doi: 10.1016/s0010-7824(02)00298-6.
37. Greenlee AR, Arbuckle TE, Chyou PH. risk factors for female infertility in an agricultural region. Epidemiology 2003; 14(4): 429-36. doi: 10.1097/01.EDE.0000071407.15670.aa.

38. Winchester PD, Huskins J, Ying J. Agrichemicals in surface water and birth defects in the United States. Acta Paediatr 2009; 98(4): 664-9. doi: 10.1111/j.1651-2227.2008.01207.x.

39. Mesnage R, Clair E, de Vendômois JS, Séralini GE. Two cases of birth defects overlapping Stratton-Parker syndrome after multiple pesticide exposure. Occup Environ Med 2010; 67(5): 359. doi: 10.1136/oem.2009.052969.

40. Mnif W, Hassine AI, Bouaziz A, Bartegi A, Thomas O, Roig B. Effect of endocrine disruptor pesticides: a review. Int J Environ Res Public Health 2011; 8(6): 2265-303. doi: 10.3390/ijerph8062265.

41. Pourhassan B, Meysamie A, Alizadeh S, Habibian A, Beigzadeh Z. Risk of obstructive pulmonary diseases and occupational exposure to pesticides: a systematic review and meta-analysis. Public Health 2019; 174:31-41. doi:10.1016/j.puhe.2019.05.024

42. Ye M, Beach J, Martin JW, Senthilselvan A. Occupational pesticide exposures and respiratory health. Int J Environ Res Public Health 2013; 10(12): 6442-71. doi: 10.3390/ ijerph10126442.

43. Panemangalore M, Dowla HA, Byers ME. Occupational exposure to agricultural chemicals: Effect on the activities of some enzymes in the blood of farm workers. Int Arch Occup Environ Health 1999; 72(2): 84-8. doi: 10.1007/ s004200050342.

44. Matsumura F. Classification of Insecticides. US: Springer; 1975. p. 45-109.

45. Kar P, Misra M. Use of keratin fiber for separation of heavy metals from water. Journal of Chemical Technology \& Biotechnology 2004; 79(11): 1313-9. doi:10.1002/jctb.1132.

46. Aluigi A, Tonetti C, Vineis C, Tonin C, Mazzuchetti G. Adsorption of copper(II) ions by keratin/PA6 blend nanofibres. European Polymer Journal 2011; 47(9): 175664. doi: 10.1016/j.eurpolymj.2011.06.009.

47. Sussman JL, Harel M, Frolow F, Oefner C, Goldman A, Toker L, et al. Atomic structure of acetylcholinesterase from Torpedo californica: A prototypic acetylcholine-binding protein. Science 1991; 253(5022): 872-9. doi: 10.1126/ science.1678899.

48. Bernstein BE, Michels PA, Hol WG. Synergistic effects of substrate-induced conformational changes in phosphoglycerate kinase activation. Nature 1997; 385(6613): 275-8. doi: 10.1038/385275a0.

49. Rojas AM, Fuentes G, Rausell A, Valencia A. The Ras protein superfamily: Evolutionary tree and role of conserved amino acids. J Cell Biol 2012; 196(2): 189-201. doi: $10.1083 /$ jcb.201103008.

50. Dvir H, Silman I, Harel M, Rosenberry TL, Sussman JL. Acetylcholinesterase: from 3D structure to function. Chem Biol Interact 2010; 187(1-3): 10-22. doi: 10.1016/j. cbi.2010.01.042.

51. Ripoll DR, Faerman CH, Axelsen PH, Silman I, Sussman JL. An electrostatic mechanism for substrate guidance down the aromatic gorge of acetylcholinesterase. Proc Natl Acad Sci U S A 1993; 90(11): 5128-32. doi: 10.1073/ pnas.90.11.5128

52. Weise C, Kreienkamp HJ, Raba R, Pedak A, Aaviksaar A, Hucho F. Anionic subsites of the acetylcholinesterase from 
Torpedo californica: affinity labelling with the cationic reagent N,N-dimethyl-2-phenyl-aziridinium. EMBO J 1990; 9(12): 3885-88. doi: 10.1002/j.1460-2075.1990. tb07607.x.

53. Hulme EC, Soper AK, McLain SE, Finney JL. The hydration of the neurotransmitter acetylcholine in aqueous solution. Biophys J 2006; 91(6): 2371-80. doi: 10.1529/ biophysj.106.089185.

54. Zeev-Ben-Mordehai T, Silman I, Sussman JL. Acetylcholinesterase in motion: visualizing conformational changes in crystal structures by a morphing procedure. Biopolymers 2003; 68(3): 395-406. doi: 10.1002/bip.10287.

55. Soulages JL, Kim K, Walters C, Cushman JC. Temperatureinduced extended helix/random coil transitions in a group 1 late embryogenesis-abundant protein from soybean. Plant Physiol 2002; 128(3): 822-32. doi: 10.1104/pp.010521.

56. Mondal R, Ghosh N, Mukherjee S. Contrasting effects of $\mathrm{pH}$ on the modulation of the structural integrity of hemoglobin induced by sodium deoxycholate. Phys Chem Chem Phys 2016; 18(44): 30867-76. doi: 10.1039/c6cp05216a.

57. Proc JL, Kuzyk MA, Hardie DB, Yang J, Smith DS, Jackson $\mathrm{AM}$, et al. A quantitative study of the effects of chaotropic agents, surfactants, and solvents on the digestion efficiency of human plasma proteins by trypsin. J Proteome Res 2010; 9(10): 5422-37. doi: 10.1021/pr100656u.

58. Pantsar T, Poso A. Binding affinity via docking: fact and fiction. Molecules 2018; 23(8): 1899. doi: 10.3390/ molecules23081899.

59. Chen D, Oezguen N, Urvil P, Ferguson C, Dann SM, Savidge TC. Regulation of protein-ligand binding affinity by hydrogen bond pairing. Sci Adv 2016; 2(3): e1501240. doi: 10.1126/sciadv.1501240.

60. Kumar S, Tsai CJ, Nussinov R. Factors enhancing protein thermostability. Protein Eng 2000; 13(3): 179-91. doi: 10.1093/protein/13.3.179.

61. Panja AS, Bandopadhyay B, Maiti S. Protein thermostability is owing to their preferences to non-polar smaller volume amino acids, variations in residual physico-chemical properties and more salt-bridges. PLoS One 2015; 10(7):e0131495. doi: 10.1371/journal.pone.0131495.

62. Liang S, Guo X, Feng N, Tian Q. Isotherms, kinetics and thermodynamic studies of adsorption of $\mathrm{Cu} 2+$ from aqueous solutions by $\mathrm{Mg} 2+/ \mathrm{K}+$ type orange peel adsorbents. J Hazard Mater 2010; 174(1-3): 756-62. doi: 10.1016/j.jhazmat.2009.09.116. 